\title{
A Single Point Assessment of Prevalence and Pattern of Sports Injuries among Young Indian Adults
}

\author{
Rashid Ishfaq, Tiwari Pramil ${ }^{*}$ \\ Department of Pharmacy Practice, National Institute of Pharmaceutical Education and Research, S.A.S. Nagar, Punjab, INDIA.
}

Received: 11 December 2018;

Accepted: 21 January 2019

*Correspondence to:

Dr. Tiwari Pramil,

Professor and Head, Department of Pharmacy

Practice, National Institute of Pharmaceutical

Education and Research SAS Nagar Mohali,

Punjab, INDIA.

Email:ptiwari@niperac.in

Copyright: (0) the author(s),publisher and licensee Indian Academy of Pharmacists. This is an open-access article distributed under the terms of the Creative Commons Attribution Non-Commercial License, which permits unrestricted non-commercial use, distribution, and reproduction in any medium, provided the original work is properly cited.

\begin{abstract}
Introduction: Participation in sports entails a risk of injury for all athletes. Sports injury ranks among the major public health problems because substantial morbidity and cost goes parallel. This study aims to assess the prevalence and patterns of sports injuries among young Indian adults. Methodology: This crosssectional study utilized a self-administered questionnaire conducted at National Institute of Pharmaceutical Education and Research, Punjab, India. The data obtained from 146 participants from sister institutions across the country is presented. A complete enumeration of the study subjects was performed. The data was computed using Microsoft excel® and free version of SPSS. Results: The studied sample had $46.5 \%$ of prevalence of sports injuries. Males were mostly affected by injuries. $40.1 \%$ of prevalence was reported among those participants who were devoid of coaching facilities. The practice of preventive measures was also low. Participants played lawn tennis followed by kabaddi and volleyball suffered more injuries. Injuries are not covered by any insurance policy; and, out of pocket expenditure was high. Conclusion: Lack of technical expertise in sports injury management is a matter of concern as large of participants reported lack of coaching facilities. The results of this study also demand that attention be paid towards preventive measures and periodic health screening to promote youngsters to continue to enjoy sports in a safer way. Finally, it may pave way for sensitization in young students at the college/school level.
\end{abstract}

Key words: Injury, Sports, Financial Dimension, Athlete.

\section{INTRODUCTION}

Sports bring fame to a nation. Promotion of a physically active lifestyle is encouraged worldwide, particularly with regard to the multiple health benefits. India is emerging as a diabetic capital. There are many advantages of sports on health like decreasing the risk of obesity, cardiovascular disease, hypertension, diabetes and improving physical fitness ${ }^{[1]}$ However, participation in sports also entails a risk of injury for all athletes.

Harm to the human body sustained while participating in sports and physical exercise is a well-recognized public health problem now a days. Any healthrelated problem has physical, psychological and economic consequences. Injuries in youth sports accounts for substantial morbidity and cost. ${ }^{[2]}$ The inability of an athlete to participate in National/International competitions due to a sports injury is attached to various health related costs and economic losses. In addition, athletes are likely to have lower performance for a long period of time because of lack of proper psychological support.

In Australia it has been reported that from 2004-2010, the associated accumulated economic burden was $\$ 265$ million for all sports injuries and $\$ 110$ million for lower limb injuries. ${ }^{[3]}$ While another study reported the average financial cost of a single HSI increased by $56 \%$ from $\$ A 25603$ in 2003 to $\$$ A40021 in 2012. ${ }^{[4]}$

In order to assess sport injuries, it is quite important to understand the risk factors behind the injuries. The potential risk factors that could increase the potential for sports injuries may be qualified as extrinsic (environment dependent) or intrinsic (athlete-dependent). Extrinsic modifiable risk factors that influence sports injury risk include sports' context, protective equipment, rules and regulations, playing surface and coaching education and training, while extrinsic non-modifiable risk factors include sport context, weather conditions, level of play, time of season and playing position. ${ }^{[5]}$ The intrinsic modifiable risk factors are fitness level, flexibility, muscle strength, joint stability, sport specific training/warm-up, balance and coordination, psychological and social factors, while intrinsic non-modifiable risk factors include age, gender, maturity level and previous injury. ${ }^{[5]}$

In India, the sports injuries in athletes deserve special attention. There are very few references of sports injury data at state or national level. The main purpose of this paper is to investigate the prevalence and pattern of sports injuries among young Indian adults at an institution of higher education.

\section{MATERIALS AND METHODS Study design, sample and setting}

This prospective cross-sectional study was conducted during February and March 2018 among students of different colleges across the country at an institution of higher education. In this study, the data from 146 participants was analyzed.

\section{Data collection procedure}

This cross-sectional study utilized a self-administered questionnaire. The verbal and written explanation of the study was performed and the written informed consent from participants prior to enrolling subjects in the study was obtained. 
The definition of sports injury in this study was "any damage to tissues as a direct result of participating in sports and exercise, which causes the frequency and/or intensity of participation to be changed or ceased". This definition includes minor sports injuries that may not receive medical treatment in addition to more severe injuries that require medical attention. ${ }^{[6]}$

The participants with age 18 to 35 years, either sex, participating in one or more games and patients willing to participate were included. The patients with incomplete documentation and unwilling to participate were excluded from the study.

All the relevant information was collected from the participant interview, which includes demographic characteristics (age, gender, body weight and height), coaching, knowledge of preventive measures, practice of preventive measures, hospitalization, duration of hospital stay, impact on daily life and any self-medication. All this information was collected in a standard case record form.

This study has been approved by director NIPER SAS Nagar, Punjab, India. The participants were not subjected to any harm during this study and there was no direct benefit to them. Information was provided about the aims and objectives of the study and the methodology adopted. Participants' rights were respected and the personal health information provided by the participant was confidential and in no circumstances it was disclosed to anyone.

\section{Data analysis}

All the data obtained during the study was organized into a spread sheet. The descriptors of central tendency and variations were computed using Microsoft Excel ${ }^{\circledR}$ and free version of SPSS. The results were presented in percentages and average supported with SEM. Binomial logistic regression was performed. $P<0.05$ was taken to indicate statistical significance.

\section{RESULTS}

In this cross-sectional study, 196 participants were involved in some kind of sports. They were evaluated by means of personal interview and selfadministered questionnaire to assess the prevalence and pattern of sports injuries among young Indian adults. 50 participants were excluded from this study (35 with incomplete information and 15 not willing to participate in the study). Therefore, the results of this study are based on data obtained from 146 participants.

Out of 146 participants, $64.4 \%$ were males and $35.6 \%$ were females. The average age of the participants was found to be $23.4 \pm 0.1$ years, with range of 21-30 years. The median age was found to be 23 years and mode was 23 years. The average age of male participants was $23.6 \pm 0.1$ years and the average age of female participants was $22.9 \pm 0.1$ years. Further, the patients were categorized into two age groups, 132 participants were belonged to " 20 -25 years" and 14 participants were from " $26-35$ years".

Among 146 participants, 104 (71.23\%) participants had BMI within normal range. Majority of the participants were devoid of coaching facilities, only $14(9.6 \%)$ had coach for their sporting activity. 111 participants were having knowledge of preventive measures regarding the sports they actively engage, among them only 83 participants were seen practicing preventive measures. (Table 1)

Cricket and Volleyball was the most popular sport with 124 and 100 participants playing it followed by badminton, 93 participants (Figure 1). The percentage of smokers and alcohol consuming participants was quite low $(10.9 \%, 15.7 \%)$.

\section{Prevalence and pattern of sport injuries}

The studied sample had overall $46.5 \%$ of prevalence. Males suffered more $(47,32.2 \%)$ sports injuries than females $(21,14.4 \%) .40 .1 \%$ of prevalence was reported among those participants who were devoid of coaching facilities. Participants played lawn tennis followed by football, kabaddi and volleyball suffered more injuries. (Figure 1)

Study participants of " $20-25$ years" of age bracket suffered more injuries than "26-30" age bracket. The prevalence of sport injuries was more among those who were devoid of coaching facilities (43.1\%). (Table 1).

Leg/foot was the most common region affected (30, 22.0\%) and the generalized body pain and cramps (30\% and 18\%) followed by sprain $(17 \%)$ was the most common injury type. (Figure $2 \mathrm{a}$ and $2 \mathrm{~b}$ ).

There were few positive outcomes of this study like only $20.5 \%$ of patients were reported to have a significant impact on their daily activities and 7.5\% of patients required hospitalization due these sports injuries. $(127,86.9 \%)$ students reported they have first aid facilities in their campus.

\section{DISCUSSION}

The results of this study are based upon data obtained from a set of 146 participants comprising a higher participation of males than females $(64.4 \%$ and $35.6 \%$ ).

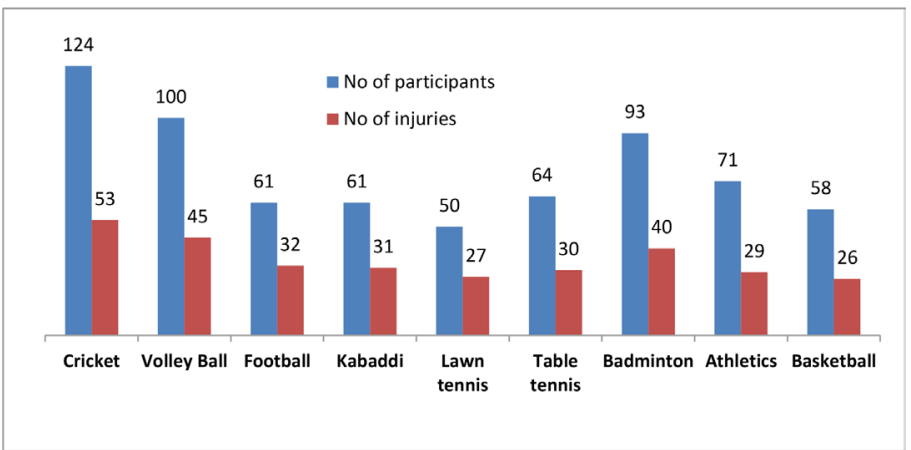

Figure 1: Profiling of study participants based on type of sport involved.

\begin{tabular}{|c|c|c|c|}
\hline \multirow{2}{*}{$\begin{array}{l}\text { Determinants of Sports } \\
\text { Injuries }\end{array}$} & \multirow{2}{*}{$\begin{array}{l}\mathbf{N}(\%) \\
146\end{array}$} & \multicolumn{2}{|c|}{ Sports Injuries (\%) } \\
\hline & & Yes & No \\
\hline $\begin{array}{l}\text { Gender Male } \\
\text { Female }\end{array}$ & $\begin{array}{l}94(64.4) \\
52(35.6)\end{array}$ & $\begin{array}{l}47(32.2) \\
21(14.4)\end{array}$ & $\begin{array}{l}47(32.2) \\
31(21.2)\end{array}$ \\
\hline $\begin{array}{l}\text { Age group (years) 20-25 } \\
26-30\end{array}$ & $\begin{array}{l}132(90.4) \\
14(9.6)\end{array}$ & $\begin{array}{l}63(43.1) \\
5(3.4)\end{array}$ & $\begin{array}{l}69(47.3) \\
9(6.2)\end{array}$ \\
\hline $\begin{array}{l}\text { Coaching Present } \\
\text { Absent }\end{array}$ & $\begin{array}{l}14(9.6) \\
132(90.4)\end{array}$ & $\begin{array}{l}5(3.4) \\
63(43.1)\end{array}$ & $\begin{array}{l}9(6.2) \\
69(47.3)\end{array}$ \\
\hline $\begin{array}{l}\text { Knowledge of PM Present } \\
\text { Absent }\end{array}$ & $\begin{array}{l}111(76.0) \\
35(24.0)\end{array}$ & $\begin{array}{l}51(34.9) \\
17(11.7)\end{array}$ & $\begin{array}{l}60(41.1) \\
18(12.3)\end{array}$ \\
\hline $\begin{array}{l}\text { Practice of PM Present } \\
\text { Absent }\end{array}$ & $\begin{array}{l}83(56.8) \\
63(43.2)\end{array}$ & $\begin{array}{l}40(27.4) \\
28(19.2)\end{array}$ & $\begin{array}{l}43(29.4) \\
35(24.0)\end{array}$ \\
\hline
\end{tabular}

(PM: Preventive measures) 


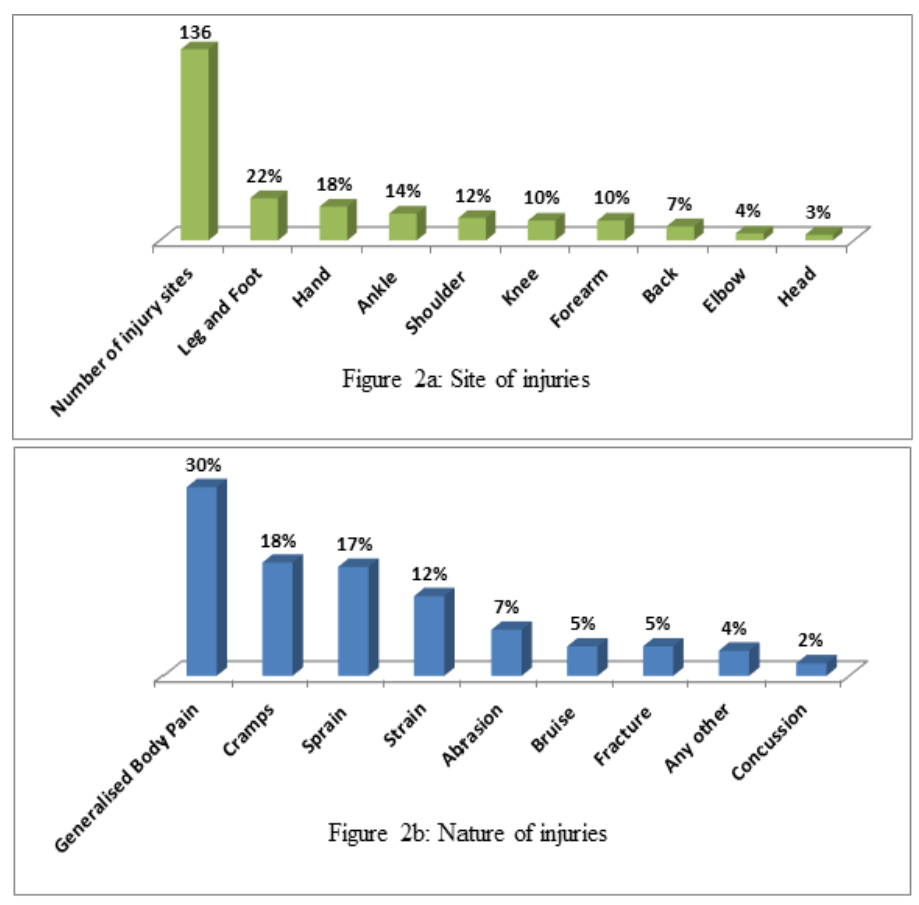

Figure 2 (a,b): Profiling of study participants based on injury pattern.

The prevalence of sports injuries in this study was found to be $46.5 \%$, which was quite smaller when compared to a similar study done in Delhi, India and West Bengal, India which have reported a prevalence of $73.4 \% 0^{[7]}$ and $58.9 \%{ }^{[8]}$ but quite higher when compared with the studies done in United States ${ }^{[9]}$ and Scotland, ${ }^{[10]}$ which had a prevalence of around $30 \%$, this could be either due to difference in sample size or characteristics of study participants. In this study, males (32.2\%) suffered more injuries than the females $(14.4 \%)$ which were in consonance with the studies conducted in Delhi, India. ${ }^{[7]}$

The prevalence of sport injuries was more among those who were devoid of coaching facilities for their sporting activities. This depicts that lack of proper technical expertise increases the risk of being injured during sports.

Injuries were more among participants who were engaged in lawn tennis (54\%), football (52.4\%), kabaddi (50.8\%) and volleyball (45\%). The commonest type of injury was generalized body pain (30\%) followed by cramps $(18 \%)$, sprain $(17 \%)$, strain $(12 \%)$ and abrasion $(7 \%)$.

In the present study, out of 68 participants who suffered injuries, only $(48,70.58 \%)$ participants took some form of treatment and among those who took treatment majority $(38,46.4 \%)$ took self-medication, who spend out of pocket for receiving treatment. This highlights the fact that the sport injuries were not covered by any insurance policy.

About the knowledge and practice of preventive measures of sport injuries, in the present study, $111(76.0 \%)$ participants claimed to have knowledge pertaining to preventive measures. Further, $83(56.8 \%)$ participants reported regular practice of the preventive measures and this proportion is quite high when compared to the results of the study conducted in Delhi, India. ${ }^{[7]}$ In the later report, only $26 \%$ of the participants reported practicing preventive measures whereas the results of the current study showed a substantially large proportion of participants practicing this.

\section{CONCLUSION}

This study was aimed to assess the prevalence and pattern of sports injuries among young India adults by self-administered questionnaire. The prevalence of sports injury was $46.5 \%$ and practice of using preventive measures was $56.8 \%$ in this study. Lack of technical expertise in sports injury management is a matter of concern as large of participants reported lack of coaching facilities. The results of this study also demand that attention be paid towards preventive measures and periodic health screening to promote youngsters to continue to enjoy sports in a safer way. This study could pave way for sensitization in young students at the college/school level. And the high prevalence among participants devoid of coaching facilities shall attract the sports scientists and physical educationists.

\section{ACKNOWLEDGEMENT}

The authors thank the officers of "National Institute of Pharmaceutical Education and Research, SAS Nagar India" for catalyzing the present study.

\section{CONFLICT OF INTEREST}

The authors declare no conflict of interest

\section{FUNDING}

Funding for this project was provided from the National Institute of Pharmaceutical Education and Research. The sponsors had no role in the design and conduct of the study; in the collection, analysis and interpretation of data; in the preparation of the manuscript; or in the review or approval of the manuscript.

\section{FINDING SOURCES}

These findings are the result of work supported by the National Institute of Pharmaceutical Education and Research, Mohali, India. The views expressed in this paper are those of the authors.

\section{ABBREVIATIONS}

NIPER: National Institute of Pharmaceutical Education and Research; SEM: Standard Error of Mean; PM: Preventive Measures.

\section{REFERENCES}

1. Pate RR, et al. Physical activity and public health: A recommendation from the Centers for Disease Control and Prevention and the American College of Sports Medicine. JAMA. 1995;273(5):402-7.

2. Bijur PE, Trumble A, Harel Y, Overpeck MD, Jones D, Scheidt PC. Sports and recreation injuries in US children and adolescents. Arch Pediatr Adolesc Med. 1995;149(9):1009-16.

3. Finch CF, Kemp JL, Clapperton AJ. The incidence and burden of hospitaltreated sports-related injury in people aged $15+$ years in Victoria, Australia, 2004-2010: a future epidemic of osteoarthritis?. Osteoarthritis and Cartilage. 2015;23(7):1138-43.

4. Hickey J, Shield A J, Williams MD, Opar DA. The financial cost of hamstring strain injuries in the Australian Football League. Br J Sports Med. 2014;48(8):729-30.

5. Theisen D, Malisoux L, Seil R, Urhausen A. Injuries in youth sports: Epidemiology, Risk factors and prevention. Dtsch Z Sportmed. 2014;65(9):248-52.

6. Bhardwaj S. Common sports injuries and their management. International Journal 
Ishfaq and Pramil.: Study About Sport Related Injuries among Young Indians

of Informative and Futuristic Research. 2013;1(3):46-55.

7. Kumar, et al. Prevalence and pattern of sport injuries among college students in Delhi, India. Saudi Journal of Sports Medicine. 2014;14(2):113.

8. Ray K, Bhattacherjee S, Akbar F, Biswas R, Banarjee R, Chakraborty M. Physical injury: A profile among municipal primary school children of Silguri, Darjeeling District. Indian J Public Health. 2012;56(1):49-52.
9. Bijur PE, Trumble A, Harel Y, Overpeck MD, Jones D, Scheidt PC. Sports and recreation injuries in US children and adolescents. Arch Pediatr Adolesc Med. 1995;149(9):1009-16.

10. Williams JM, Wright P, Currie CE, Beattie TF. Sports related injuries in Scottish adolescents aged 11-15. Br J Sports Med. 1998;32(4):291-6.

Cite this article as: Ishfaq R, Pramil T. A Single Point Assessment of Prevalence and Patterns of Sports Injuries among Young Indian Adults. J Pharm Pract Community Med. 2019;5(1):18-21. 